\title{
Ensino de estatística e tecnologias da informação e comunicação: entre a docência e o desenvolvimento de recursos tecnológicos
}

Cristiane de Fatima Budek Dias cristianebudekdias@gmail.com 0000-0003-0376-0905

Universidade Tecnológica Federal do Paraná, Ponta Grossa, Paraná, Brasil.

\section{Guatacara dos Santos Junior} guata@utfpr.edu.br

Tecnónica Federal do Paraná, Ponta Grossa, Paraná, Brasil.

\section{RESUMO}

Este artigo tem como objetivo apresentar a análise de um encontro com professores dos anos iniciais do Ensino Fundamental em que os mesmos foram convidados a participar do processo de desenvolvimento de um Ambiente Virtual de Aprendizagem - AVA para o ensino de Estatística. O estudo de cunho qualitativo e interpretativo, é parte de uma pesquisa de mestrado em andamento, sendo que, neste escrito são apontadas algumas das percepções preliminares com tal prática. Dessa forma, as considerações sobre trabalho realizado com os professores foram elencadas em categorias que evidenciam: i) atitudes docentes em relação às TIC; ii) atitudes em relação à análise e a coparticipação na construção do AVA; iii) concepções e atitudes em relação à Estatística e Probabilidade; iv) percepções sobre as ferramentas do AVA. Esse encontro com os professores revelou muitos obstáculos, tanto na compreensão da proposta como no entendimento a respeito de Probabilidade e Estatística, sugerindo que processos de formação continuada que se atentem mais aos aspectos da autonomia do professor e dos saberes básicos da docência na atualidade, sejam priorizados.

PALAVRAS-CHAVE: TIC. Professores. AVA. Estatística. Probabilidade. 


\section{INTRODUÇÃO}

A Educação Estatística se faz primordial nos tempos de hoje, em que inúmeras informações demonstradas estatisticamente são expostas nas mídias televisivas, impressas e na Internet. Cada vez mais o ser humano depare-se com dados e representações gráficas e tabulares sobre os mais diversos assuntos da vida cotidiana: a economia, a política, as questões sociais, esportivas, o clima etc. Dessa forma, é importante que compreenda essas representações para que um olhar mais crítico seja possibilitado.

Kenski (2012, p. 11) menciona que "a informação veiculada em jornal, revista ou livro não envolve a totalidade de informações sobre determinado assunto e nem pode ser considerada totalmente isenta ou imparcial." A mensagem sempre será exposta de acordo com as concepções do autor sobre os fatos. E isso não ocorre de maneira diferente quando se trata de informes estatísticos veiculados nos meios de comunicação.

Muitos dados são representados de forma tendenciosa nos meios midiáticos, trazendo certas armadilhas que o cidadão precisa desarmar e isso só é possível com conhecimentos básicos de Estatística (CASTRO \& CAZORLA, 2008).

Assim, pensando na efetividade de uma Educação Estatística que agregue valores fundamentais aos alunos é que se propõe uma prática alicerçada nas Tecnologias da Informação e Comunicação - TIC, com produção e veiculação de informações que demonstrem o trabalho do professor e as interpretações dos alunos.

Tem-se por pressuposto que em propostas baseadas nas TIC a aprendizagem não se reduz a aspectos técnicos de utilização da tecnologia, nem conduz o aluno à simples recepção do currículo preestabelecido. Experiências educativas permeadas pelas TIC facilitam o acesso a diferentes perspectivas sobre os mesmos assuntos, aumentam a capacidade de comunicação e invertem a concepção sobre criação e autoria (KENSKI, 2012).

O que se percebe, entretanto, é que, apesar da grande variedade de softwares e demais ferramentas tecnológicas para o ensino, muitos acabam sendo deixados de lado ou ainda apresentam falhas que inviabilizam sua utilização pelos professores. Aliado a isso, está a falta de uma formação mais completa dos professores para que as tecnologias sejam incorporadas com efetividade ao trabalho em sala de aula.

Nesse sentido, é que se propôs a construção de um Ambiente Virtual de Aprendizagem (AVA) para o ensino de Probabilidade e Estatística para os anos iniciais do Ensino Fundamental e, entendendo que a construção de softwares educativos não deve ficar restrita a empresas comerciais e a especialistas em informática, propôs-se a construção conjunta com professores, pedagogos e desenvolvedores. Tem-se por pressuposto que o professor não deve ser apenas um "usuário crítico, mas também um projetista" (ALMEIDA, 2012, p. 31). É nessa linha de raciocínio que buscou-se fundamentar o presente estudo, oportunizando a professores atuantes a participação ativa na construção do AVA.

Este artigo tem como objetivo apresentar a análise de um encontro com 
convidados a participar do processo de desenvolvimento de um Ambiente Virtual de Aprendizagem - AVA, para o ensino de Estatística.

\title{
PROFESSORES E TECNOLOGIAS DA INFORMAÇÃO E COMUNICAÇÃO (TIC)
}

Como sabe-se a incorporação efetiva das TIC no processo educativo nas escolas brasileiras ainda abarca muitos desafios, que vão desde a elaboração e execução de projetos e políticas públicas que garantam um mínimo de infraestrutura às instituições, até a formação crítica do docente para a escolha, a avaliação e o uso coerente das tecnologias.

Há de se enfrentar ainda a resistência de alguns professores e gestores frente às mudanças exigidas com a revolução que se presencia. Para Ponte (2000) é possível encontrar diversas atitudes entre os docentes no que se refere às TIC:

\begin{abstract}
Alguns, olham-nas com desconfiança, procurando adiar o máximo possível o momento do encontro indesejado. Outros, usam-nas na sua vida diária, mas não sabem muito bem como as integrar na sua prática profissional. Outros, ainda, procuram usá-las nas suas aulas sem, contudo, alterar as suas práticas. Uma minoria entusiasta desbrava caminho, explorando incessantemente novos produtos e ideias, porém defronta-se com muitas dificuldades como também perplexidades (PONTE, 2000, p. 64).
\end{abstract}

Essa diversidade de atitudes demonstram o quão labiríntico é o processo de incorporação das TIC na educação. Professores enfrentam desafios que acabam trazendo incertezas a respeito do valor a ser agregado em suas práticas didáticopedagógicas quando se faz o uso das tecnologias da informação e comunicação.

Freitas (2010, P. 341) afirma que "muitas vezes os docentes adotam uma posição defensiva e às vezes até negativa, no que se refere às mídias e às tecnologias digitais, como se pudessem deter seu impacto e afirmar o lugar da escola e o seu como detentores do saber. " Isso é decorrente, em muitos casos de uma formação inicial deficitária, que não prepara os docentes para o uso pedagógico das TIC.

Há dúvidas sobre o que, o quando e o como utilizar. E também desassossegos sobre seu próprio papel frente ao avanço dessas tecnologias, em que a informação se faz presente e circula cada vez com mais velocidade.

Kenski (2012) aponta que um dos grandes desafios enfrentados pelos professores reside extremas: dos alunos que já possuem conhecimentos avançados e acesso pleno às últimas inovações tecnológicas aos que se encontram em plena exclusão tecnológica; das instituições de ensino equipadas com as mais modernas tecnologias digitais aos espaços educacionais precários e com recursos mínimos para o exercício da função docente. O desafio maior, no 
O fato é que as TIC desencadeiam novas relações dos atores educativos com o saber, novas formas de interação entre professores e alunos e uma nova maneira de integração docente na organização escolar e na profissão. Nesse sentido, as responsabilidades se alargam: à docência cabe agora uma função educativa primordial. Professores precisam assumir um novo papel, o de "co-aprendentes com os seus alunos, com os seus colegas, com outros actores educativos e com elementos da comunidade em geral." (PONTE, 2000, p. 77).

Freitas (2010), aponta para a necessidade do diálogo entre as duas culturas: nativos digitais (alunos) e imigrantes digitais (professores) que se "defrontam e se confrontam com experiências diversas em relação às tecnologias digitais" (FREITAS, 2010, p. 342). Para a autora o professor precisa estar receptivo ao novo, pois assim poderá investigá-lo, compreendendo o que ele pode trazer para o ensino e para a aprendizagem.

O professor "imigrante digital" tem em sua frente o aluno "nativo digital" e precisa saber lidar com isso (FREITAS, 2010). De acordo com Kenski (2012) a educação tem um duplo desafio: "adaptar-se aos avanços da tecnologia e orientar o caminho de todos para o domínio e a apropriação crítica desses novos meios." Esse é um caminho que precisa ser trilhado pela educação da atualidade, portanto, é um processo que se desdobra no presente.

Além disso, domínio e apropriação crítica das TIC não são aspectos a serem pensados somente na dimensão do aluno, pois o professor, como co-aprendente, também precisa dominar e, sem dúvida, ter uma apropriação crítica das tecnologias. É fundamental que o docente tenha uma visão clara das mudanças e das potencialidades que se abrem para seu trabalho e também que consiga compreender aquilo que poderá ser útil ou não. Precisa haver reflexão sobre as TIC e seus desdobramentos e consequências.

Ponte (2000, p. 89) alerta, porém, que

\footnotetext{
Criticar as TIC sem as compreender ou condicionado pelo receio será sempre inconsequente e ineficaz. A capacidade crítica em relação às tecnologias pressupõe intimidade com as próprias tecnologias. O desafio é usar plenamente a tecnologia sem se deixar deslumbrar. Consumir criticamente. Produzir criticamente. Interagir criticamente. Estimular a crítica das tecnologias e dos seus produtos.
}

De fato, compreensão e um olhar para além do "medo" são imprescindíveis para a crítica. Tanto as TIC como as mudanças que proporcionam no cotidiano das pessoas necessitam ser compreendidas. Não se pode duvidar de que as TIC desencadearam mudanças consideráveis e também positivas para a educação. Muitos recursos de áudio, vídeo, softwares, jogos e tantos outros, modificam a 
realidade da aula, dinamizando o espaço do ensino e da aprendizagem (KENSKI, 2012). Todavia, mesmo em um processo de incorporação das TIC nas escolas, não se pode garantir a transformação das práticas docentes (CIBOTTO \& OLIVEIRA, 2013).

Para que mudanças expressivas realmente possam ser contempladas no processo educativo, as TIC necessitam de compreensão e de uma incorporação pedagógica no espaço escolar. "Isso significa que é preciso respeitar as especificidades do ensino e da própria tecnologia para poder garantir que o seu uso, realmente, faça a diferença. Não basta usar a televisão ou o computador, é preciso saber usar de forma pedagogicamente correta a tecnologia escolhida." (KENSKI, 2012, p. 35).

Dessa forma, a verdadeira incorporação das TIC no processo de ensino requer do professor conhecimentos específicos, em que as dimensões do conhecimento do conteúdo, da prática pedagógica e da tecnologia estejam imbricadas. Entende-se, dessa maneira, que os professores necessitam tanto de preparo técnico como de preparo pedagógico para que consigam integrar as tecnologias em suas aulas (QUARTIERI et al, 2015).

Mishra e Koehler (2006) apontam que a questão central é entender o que os docentes necessitam saber para a integração adequada da tecnologia em suas práticas pedagógicas. Nesse sentido apresentam a teoria do Conhecimento Pedagógico e Tecnológico do Conteúdo - TPACK (do inglês Technological Pedagogical Content Knowledge) que é baseada na teoria de Shulman (1986) do Conhecimento Pedagógico do Conteúdo (PCK).

O modelo proposto por Mishra e Koehler (2006), aponta que o conhecimento sobre o conteúdo $(C)$, pedagogia $(P)$, e tecnologia $(T)$ são centrais para o desenvolvimento de um bom ensino. Todavia, não se trata de considerá-los como corpos isolados de conhecimento: no modelo TPACK, enfatiza-se a complexa interação destes três corpos de conhecimento.

Dessa forma, devem ser vistos em pares: Conhecimento Pedagógico do Conteúdo (PCK), Conhecimento Tecnológico do Conteúdo (TCK), Conhecimento Pedagógico Tecnológico (TPK), e desse conjunto a tríade Conhecimento Tecnológico Pedagógico do Conteúdo (TPACK).

A tríade Conhecimento Tecnológico Pedagógico do Conteúdo é uma forma de conhecimento que permite reconhecer possíveis formas de ensinar com a tecnologia. Esse conhecimento ultrapassa o entendimento e o domínio dos conhecimentos pedagógicos, tecnológicos e de conteúdo isoladamente. Os autores apontam que o TPACK é o alicerce para o "bom ensino" com a tecnologia, requerendo uma compreensão da 
do que torna conceitos difíceis ou fáceis de serem aprendidos e de como a tecnologia pode ajudar a resolver alguns dos problemas que os alunos enfrentam; o conhecimento acerca do conhecimento prévio que os alunos possuem, e teorias epistemológicas; conhecimento de como tecnologias podem ser usadas para construir o conhecimento existente e desenvolver novas epistemologias ou fortalecer as antigas. (MISHRA \& KOEHLER, 2006, p. 1028).

De acordo com Lang e González (2014) nesse conhecimento estaria incluso o discernimento para reconhecer quais conteúdos seriam mais ou menos difíceis de ensinar com a utilização ou não de alguma tecnologia.

Mishra e Koehler (2006) apontam que não deve ser o uso das TIC que deve ditar o conteúdo que deve ser ensinado, mas pelo contrário, o conteúdo é que deve guiar o uso de determinada TIC. “Assim, após definir o conteúdo, poderá ser associado a um conhecimento pedagógico que servirá de base para a escolha de uma TIC para então ser trabalhada nos ambientes de ensino." (LANG \& GONZÁLEZ, 2014, p. 2)

Entende-se, portanto que, conhecendo o conteúdo o professor parte para o trato pedagógico do mesmo com o uso de ferramentas tecnológicas que potencializem sua abordagem e facilitem a aprendizagem.

Destarte, acredita-se que, para um efetivo processo de formação que atenda aos conhecimentos elencados nessa teoria, é crucial um olhar mais atento aos processos formativos em curso, que, frequentemente apresentam ferramentas tecnológicas já elaboradas para que delas os professores façam o uso. Nesse sentido, é que se propõe um espaço em que o docente possa conhecer a ferramenta em seu processo de criação, opinando e garantindo que suas necessidades sejam atendidas.

\section{ENTRE O USO DA TECNOLOGIA E O DESENVOLVIMENTO DE RECURSOS TECNOLÓGICOS}

O que se observa no contexto atual, é uma formação em que os professores estudam a informática na educação, mas não são envolvidos em atividades de efetivo uso das TIC como aportes para a aprendizagem. (FREITAS, 2010).

Dessa forma, considerando as possibilidades de ação docente e das relações entre professores e alunos e professores e professores que se alargam com o avanço das TIC, faz-se primordial pensar para além de práticas formativas em que os professores apenas "aprendem" a utilizar softwares e ferramentas já elaboradas, sem a possibilidade de inserção de sua própria visão sobre as mesmas.

Professores e alunos não podem ser meros consumidores, mas também produtores. E, para além de produzir, também interagir. Integrando-se a novas comunidades, criando novos significados, desenvolvendo novas identidades e, tudo isso, em espaços mais abrangentes (PONTE, 2000). 
É importante, então oportunizar ao professor um contato mais aprofundado com alguns softwares educativos, mas também proporcionar espaços para que possam avaliar criticamente esses instrumentos, assim como também instigá-los na produção e coprodução de páginas da web, jogos, softwares, entre outros. Professores como produtores ativos de recursos que se adequem as suas necessidades específicas.

Kenski (2012, p. 34) menciona que a "escolha de determinado tipo de tecnologia altera profundamente a natureza do processo educacional e a comunicação entre os participantes.". Dessa forma, acredita-se que o professor necessita saber avaliar as tecnologias de que fará uso. No caso de recursos computacionais, é preciso que ele conheça e tenha um olhar crítico sobre a ferramenta, ponderando suas potencialidades e suas falhas nos conhecimentos que apresenta. Assim, colocar os professores como projetistas é uma questão fundamental. Esses profissionais não podem ficar a mercê de tudo que já está pronto e acabado. Precisam saber avaliar o que já existe e criar novas possibilidades de acordo com o perfil de seus alunos. De acordo com seu próprio perfil docente.

Nessa linha de raciocínio Almeida (2012) aponta que

\begin{abstract}
Do mesmo modo que o professor é capaz de montar uma apostila sobre determinada unidade, ou escolher textos para ilustrar e aprofundar suas aulas e até produzir materiais instrucionais para revisão, fixação ou recuperação, ele poderá ser um projetista que propõe materiais a serem programados, aos quais ele pode criticar, recompor, aumentar, usar parcialmente etc. (ALMEIDA, 2012, p. 31).
\end{abstract}

O autor acredita que a "capacidade de saber o que quer e de projetar o perfil de seu material é que permite ao professor se assenhorear do instrumento, utilizálo eficaz e criativamente.". (ALMEIDA, 2012, p. 32). Ou seja, oportunizando ao professor que atua em sala de aula, que o mesmo possa dizer o que quer e de que forma pretende trabalhar com determinado recurso tecnológico, colocando-o como corresponsável por aquilo que será construído, poderá trazer ganhos mais significativos quando se trata do uso pedagogicamente correto dos mesmos. O docente terá a oportunidade de opinar sobre e de auxiliar no desenvolvimento daquilo que realmente será útil em sua prática.

Almeida (2012) ainda reflete que nessa perspectiva, o computador, auxiliar no trabalho docente, também contribuiria no repensar dos problemas educacionais, no desenvolvimento da competência dos professores e "até poderia representar uma modesta, porém, eficaz contribuição para a melhoria do próprio nível da educação escolar." (ALMEIDA, 2012, p. 32).

Essa participação mais ativa na construção das ferramentas permite que o professor consiga relacionar conteúdos, objetivos e estratégias pedagógicas para um bom uso das TIC em sua prática. Permite, ainda uma reflexão sobre a aprendizagem dos alunos (GUEDES \& GUEDES, 2004).

Não se trata aqui de formar professores experts em desenvolvimento de sistemas, com conhecimentos em graus elevados sobre a linguagem de programação, mas de um trabalho multidisciplinar, que envolva profissionais de diferentes áreas e que considere especificamente o espaço do professor, seu conhecimento e sua prática. Um processo de ouvir o que o professor tem a dizer durante a construção de determinada ferramenta. 
Outra questão importante é oferecer a oportunidade para que os docentes possam dar continuidade às ferramentas. Proporcionando meios em que os mesmos possam agregar conteúdos, expor seus conhecimentos e suas práticas em sala de aula. Também é proveitoso que haja espaço para a comunicação com outros colegas de profissão.

\section{METODOLOGIA}

Em consideração às propostas evidenciadas pelos autores acima citados é que se propôs a construção de um Ambiente Virtual de Aprendizagem (AVA) para o ensino de Estatística nos anos iniciais do Ensino Fundamental, em que os professores em exercício foram convidados a participar. O encontro ocorreu no final do mês de novembro de 2015, no polo presencial da Universidade Aberta do Brasil (UAB) com professores de uma escola do município de Ponta Grossa/PR.

Nesse primeiro encontro tentou-se fazer com que os professores pensassem sobre o conteúdo para que pudessem colaborar com o levantamento de requisitos (funcionalidades) do AVA, seguindo a perspectiva apontada por Mishra e Koehler (2006). Dessa forma, os docentes deveriam, partindo do conhecimento do conteúdo de Probabilidade e Estatística, indicar os usos pedagógicos que fariam da ferramenta para que a mesma pudesse atender aos seus anseios e facilitar a aprendizagem de seus alunos.

Destarte, nesta prática vislumbrou-se um conhecimento da realidade docente em relação ao ensino de Probabilidade e Estatística e também ao uso das TIC nesse processo. Para tanto, tentou-se responder a questões como: Quais são as atitudes dos docentes do grupo pesquisado em relação às TIC? Como compreendem a participação ativa na construção de uma ferramenta tecnológica para o processo de ensino? Como percebem a ferramenta como auxiliar em suas práticas? Quais são suas percepções e atitudes frente à Probabilidade e Estatística?

Os dados foram coletados a partir da observação dos pesquisadores durante o decorrer das ações propostas e também por meio de anotações escritas de algumas das falas dos pesquisados no diário de bordo. Também foram consideradas algumas das produções escritas dos professores, geradas com a prática. Esta pesquisa sugere uma análise de dados qualitativa e interpretativa. Assim, buscou-se analisar os dados e os discursos gerados pelos professores no decorrer das ações propostas. Diante disso, a pesquisa em questão tem características qualitativa e interpretativa, uma vez que suas análises estão baseadas na interpretação das situações, dos envolvidos na pesquisa e do meio em que a mesma foi desenvolvida.

Para responder às questões desta pesquisa, elencou-se, a priori, algumas categorias de análise:

1) Atitudes dos docentes em relação às TIC: nesta categoria foram consideradas algumas observações e falas dos professores a respeito de como percebem o uso das TIC e de como as utilizam em sua vida pessoal e profissional;

2) Atitudes em relação à análise e coparticipação na construção do AVA: esta categoria tenta responder a como os professores compreendem a participação na construção do AVA, também evidencia suas atitudes frente a proposta do próprio encontro; 
3) Atitudes em relação à Estatística e Probabilidade: esta categoria aponta algumas das percepções frequentes observadas no que diz respeito à Estatística e Probabilidade, ou seja, como os professores entendem a temática e quais conhecimentos possuem do conteúdo e da prática;

4) Percepções e aprofundamentos em relação às ferramentas do AVA: evidencia algumas das percepções aprofundadas a respeito da ferramenta em construção, elencando possibilidades para além daquelas propostas pelos pesquisadores.

\section{DISCUSSÃO DOS RESULTADOS}

Aqui são apresentados os resultados obtidos com a prática realizada, de acordo com as questões desta pesquisa e das categorias elencadas na metodologia deste artigo.

\section{1) Atitudes docentes em relação às TIC:}

Durante a realização do encontro com os professores, foi possível identificar algumas das atitudes em relação às TIC. Já de início, uma professora mencionou que precisaria de auxílio, pois não tinha familiaridade com o computador. No decorrer das etapas do encontro observou-se que a mesma tinha dificuldades para alguns comandos básicos na máquina. Assim também aconteceu com mais alguns dos participantes.

Freitas (2010) menciona que muitas vezes há preocupação com o uso da tecnologia em sala de aula, mas se deixa de lado a própria questão do letramento digital do professor, que se faz necessário e imprescindível para o aprofundamento das propostas educativas vinculadas às TIC. Nessas observações se verifica a falta do conhecimento da tecnologia, conforme apontado por Mishra e Koehler (2006, 2008), fundamental quando se trata da integração de recursos tecnológicos à prática educativa.

Uma atitude bastante frequente notada entre os participantes do encontro foi o receio e a desconfiança. Que pode ser ilustrado com as frases:

\footnotetext{
Precisa imprimir, porque a criança tem que manipular a atividade, a folha da atividade. Que se pudesse imprimir a história para poder utilizar em sala de aula porque com o conteúdo em mãos o aluno interage e se interessa mais sobre o tema. Imprimir a história para utilizar em sala de aula porque é interessante ter o conteúdo como forma de motivação e de prender a atenção.
}

Essas frases revelam também a tentativa de adiar "o momento do encontro indesejado" (PONTE, 2000, p. 64) ou até mesmo de defender seu próprio espaço dentro da escola e do processo de ensino (FREITAS, 2010).

É evidente que materiais manipuláveis são essenciais para o processo de ensino e aprendizagem, ainda mais quando se trata de crianças da faixa etária dos anos iniciais do Ensino Fundamental, no entanto, acredita-se que não seja apenas manipulando o papel em que está descrita a atividade que esse processo terá êxito. Quando se trata de integrar as TIC no ensino não quer dizer que as práticas 
produtivas e necessárias já existentes devam ser abandonadas, mas que a elas possam ser acrescentadas o novo (FREITAS, 2010).

$\mathrm{Na}$ apresentação de uma das ferramentas do AVA, destinada à postagem de planos de aula com conteúdos referentes à Estatística questionou-se os docentes a respeito do controle de acesso a esses planos de aula. Em uma das falas pode-se verificar o tipo de utilização frequente da Internet pela professora: "Acho que todos podem ter acesso, porque é muito ruim quando a gente entra num site e vê alguma coisa legal e aparece aquela mensagem de só pode quem é cadastrado".

Essa é também uma das atitudes apontadas por Ponte (2000), em que professores utilizam a Internet em seu cotidiano, porém sem incorporá-las em sua prática com os alunos. Muitos buscam na rede modelos de aulas e de materiais que podem ser úteis em sua sala de aula.

Ponte (2000) afirma que, além da relação professor e aluno, a forma como o docente se relaciona com seus colegas de profissão pode sofrer mudanças com as TIC. Para o autor as possibilidades de trabalho colaborativo, a interação com profissionais de outras escolas e com organizações educativas, são favorecidas com a Internet. Ainda destaca que muitos professores já perceberam essas possibilidades e delas já usufruem, obtendo muitos resultados favoráveis. Para o autor "Isso permite que se estabeleça um diálogo aprofundado com estes professores e mesmo com os seus alunos, quando o trabalho destes é publicado num Website." (PONTE, 2000, p. 81).

Duas professoras presentes no encontro possuem Blogs, nos quais compartilham suas ideias e as práticas que realizam em sala de aula. Essas são atitudes positivas de comunicação com a sociedade. A Internet é uma porta que se abre para que essa comunicação seja facilitada (PONTE, 2000). O professor não pode ficar a mercê apenas de modelos prontos que outros profissionais da área publicam, podem ser produtores de modelos e também podem comunicar seus resultados.

\section{2) Atitudes em relação à análise e a coparticipação na construção do AVA:}

Como o propósito fundamental do encontro foi o de colocar os professores como coparticipantes no processo de construção do AVA, nesta categoria elencam-se algumas de suas atitudes demonstradas durante a apresentação das propostas para esse instrumento.

As ações do encontro seguiram um roteiro previamente elaborado, em que, cada uma das ferramentas propostas para o AVA foi demonstrada, explicitada e discutida com todos os participantes. Os professores poderiam opinar, sugerir melhorias e também elencar equívocos. Foi proposto que descrevessem o que necessitam dentro de cada uma das ferramentas. Esse último processo, após discutido, deveria ser escrito em um cartão complementando-se a frase: "Eu, como professor, quero..., porque....".

Essa definição do anseio do professor e do motivo pelo qual necessita de funcionalidade específica para determinada ferramenta do AVA é fundamental para seguir no processo de construção. Por isso, não basta apenas dizer o que se quer, mas o porquê disso, pois assim se compreende melhor a real necessidade do professor. 
Como o AVA ainda estava em construção, as ferramentas ainda não estavam prontas no dia do primeiro encontro e isso, justamente para que os docentes em exercício pudessem auxiliar nessa construção. Entretanto, isso acabou gerando algumas dúvidas nos professores e, pode-se dizer até mesmo um receio, frente ao que se propunha. A todo momento era preciso retomar a proposta e explicar que ainda não estava pronto para que pudessem avaliar a proposta e opinar sobre o desenvolvimento do AVA.

A equipe pedagógica da escola, que também participava do encontro, apontou que isso poderia estar relacionado à inversão da dinâmica com que frequentemente os professores recebem cursos de formação continuada voltados às TIC. Essa colocação é evidenciada nas frases:

Eles não estão acostumados com isso de dizerem o que eles querem, de ajudar a construir.

Com isso, percebe-se a necessidade de processos de formação continuada que ouçam mais o professor, que os coloquem como construtores de materiais didático-pedagógicos que envolvam as TIC (ALMEIDA, 2012). Receber um software pronto e um treinamento para seu uso não basta para que ações mais efetivas de incorporação das TIC sejam vistas nas escolas. (GUEDES \& GUEDES, 2008; LANG \& GONZÁLEZ; 2014)

\section{3) Concepções e atitudes em relação à Probabilidade e Estatística:}

Durante as práticas realizadas no encontro, foram notadas algumas das concepções dos professores sobre a Estatística e a Probabilidade e também sobre o trabalho que pode ser realizado partindo do levantamento de dados.

A Estatística possui uma natureza interdisciplinar, que garante que os mais diversos assuntos possam ser abordados partindo-se do levantamento de dados, da representação gráfica e da análise e interpretação desses dados (LOPES, 2008). Essa característica interdisciplinar pôde ser observada nos planos de aula construídos pelos professores em um dos momentos do encontro.

Uma das equipes, entretanto, optou por um plano de aula com foco na Geometria. Na tentativa de auxiliar essa equipe, tentou-se explicar que uma tabela poderia ser criada, comparando-se as figuras e tabulando esses dados. Na tabela poderiam ser descritos quantos vértices e arestas cada uma possuía, entretanto, apesar do plano ser para uma turma de 50 ano, os professores da equipe discordaram, argumentando que essas nomenclaturas não fazem parte dessa fase do ensino, apenas nos anos finais do Ensino Fundamental é que são abordados esses conceitos matemáticos. Aqui se verifica a linearidade com que os conhecimentos matemáticos são frequentemente abordados, a falta de propostas mais desafiadoras aos alunos e também a dificuldade de trabalho com a Estatística e as representações gráficas e tabulares.

Bianchini (2014, p. 8) assinala que a "vivência de uma matemática constituída linearmente, que privilegia os números e as operações, pautada no paradigma do exercício, faz com que ainda hoje, seja este o entendimento que temos a respeito do trabalho a ser desenvolvido em matemática." A autora alerta que essa prática aos distintos campos matemáticos. (BIANCHINI, 2014). 
Superar essa visão linear não é tarefa fácil, mas pode ser conseguida, com uma prática mais efetiva da estocástica nas salas de aula, pois esse trabalho pode partir de problemáticas reais diversas que não se restrinjam a um ano de escolaridade específico (LOPES, 2008). Nessa perspectiva Bianchini (2014) defende que um trabalho de educação estatística crítica, tendo como ponto de partida as práticas sociais, pode também contribuir para, ao menos amenizar, essa linearidade, trazendo a estatística como elemento norteador para os conceitos matemáticos.

Alguns professores acreditam que Estatística e Probabilidade é assunto muito complexo e que não é conteúdo a ser abordado já no primeiro ano de escolaridade: "Mas isso não trabalha com os alunos do primeiro ano né? Eles são muito pequenos." De acordo com os documentos oficiais e o próprio caderno de Educação Estatística do PNAIC (2014), esse é um tema a ser abordado já no ciclo de alfabetização, que compreende o 1ㅇ, 2으 e 3 anos do Ensino Fundamental. Santos e Ponte (2013) em um estudo com professores em formação inicial para a atuação com alunos da faixa etária dos anos iniciais, relatam a dificuldade dos professores em flexibilizar materiais e conceitos estatísticos para as crianças pequenas.

Subentende-se, então, que o desafio é atentar-se para a complexidade com que os conhecimentos estatísticos devem ser apresentados às crianças. É certo que no ciclo de alfabetização muitos dos conceitos dessa área não precisam ser apresentados com profundidade, mas precisam estar presentes para que o raciocínio estatístico comece a ser desenvolvido.

Durante o encontro, surgiram perguntas como: "O que é tabela de dupla entrada?" E, em certa ocasião alguns professores discutiam sobre o que seria a Estatística. Até que se questiona: “O que é a Estatística?" Nessas falas se intensifica a ideia de que muitos não compreendem de que se trata o conhecimento estatístico e seus conceitos. Isso reforça a necessidade de cursos de formação continuada mais abrangentes, que além do conhecimento pedagógico também abordem o conhecimento do conteúdo, ou seja dos conceitos estatísticos. Shulman (1986), assim como Mishra e Koehler (2006) apontam para a relevância de que os professores conheçam o conteúdo que irão abordar com seus alunos. Certamente os professores devem ter conhecimento e compreensão acerca dos assuntos que ensinam, incluindo-se "o conhecimento do fatos centrais, conceitos, teorias e procedimentos dentro de uma determinada área; conhecimento dos quadros explicativos que organizam e conectam ideias; e conhecimento das regras de evidência e prova." (MISHRA; KOEHLER, 2006, p. 10).

Dessa forma, entende-se que para conseguir uma abordagem coerente da Estatística e Probabilidade em sala de aula, o professor precisa conhecer e entender os conceitos fundamentais dessa ciência. Lopes $(2008$, p. 71$)$ afirma que o professor necessita de "um nível de abstração superior, no que diz respeito ao conteúdo que irá trabalhar, pois somente dessa forma conseguirá estabelecer conexões com outras áreas e/ou com o próprio conhecimento matemático e estatístico".

Em seu estudo sobre as concepções de professores dos anos iniciais sobre o ensino de Estatística Vieira, Junior e Neto (2013) apontam a insegurança dos professores ao conceituar a Estatística e alertam para a necessidade de qualificação desses professores no sentido de aprofundar o conhecimento 
estatístico, de forma que venham a entender seu papel no processo de construção desse conhecimento na educação básica.

Percebeu-se, nas falas dos professores um certo desconhecimento sobre o tema abordado. Também foi possível verificar que é uma temática pouco trabalhada, levando em consideração as dificuldades na realização dos planos de aula e a ênfase em outros conteúdos ou assuntos de outras áreas sem uma interligação clara e mais produtiva com a Probabilidade e Estatística. O foco, na maioria das vezes, não está nos conceitos Estatísticos.

Um dos planos, por exemplo, aponta como tema os "Sólidos Geométricos" e na descrição dos conteúdos estão postos: "Comparação dos sólidos com os polígonos regulares e irregulares". Para a metodologia a ser utilizada até é proposta a construção de uma tabela e um gráfico, porém sem uma explicitação clara de como essa proposta seria conduzida. Também não há clareza sobre os conceitos estatísticos que seriam estimulados com o plano proposto. Por tratar-se de um planejamento para o 5 - ano, acredita-se que outros desafios poderiam ter sido propostos aos alunos.

Em seu estudo com professores em formação inicial Santos e Ponte (2013) apresentam situação semelhante: os autores apontam que os estudantes pesquisados relacionaram temas de Ciências, Ciências Sociais e Literatura, entretanto a síntese dos dados fica restrita a um sumário descritivo de fatos gerados. Alertam para a necessidade de que o planejamento seja apropriado para que os alunos compreendam o porquê da investigação Estatística e do porquê os dados são necessários.

É claro que, por sua natureza interdisciplinar, a Estatística pode ser vinculada aos conteúdos de outras áreas, entretanto, é importante oportunizar aos alunos as questões específicas de leitura, de construção, interpretação e análise dos conceitos e representações estatísticas. Esse aspecto não foi evidenciado em nenhum dos planos de aula elaborados pelos participantes do primeiro encontro. Bianchini (2014) também revela a dificuldade dos professores em articular os conceitos estatísticos aos demais blocos de conhecimentos matemáticos propostos no currículo dos anos iniciais e às demais áreas do conhecimento.

\section{4) Percepções sobre as ferramentas do AVA:}

Alguns participantes foram além nas propostas discutidas para as ferramentas do AVA, como a equipe pedagógica, que viu na ferramenta do fórum, uma oportunidade para a formação continuada dos professores da escola:

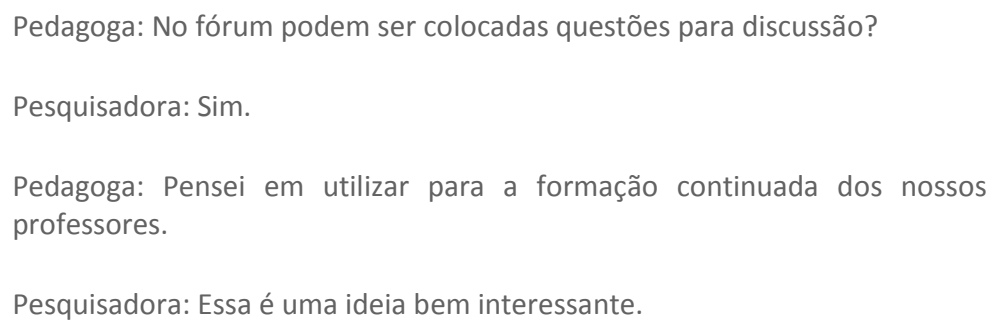


Isso demonstra que a pedagoga compreendeu a ferramenta, articulou com sua necessidade e viu uma oportunidade de realizar discussões com seus professores com o propósito de uma formação continuada. Esse é um dos ganhos quando se traz a ferramenta ainda em construção para dentro da escola. A pedagoga conseguiu refletir sobre o que precisa e porque precisa disso. Essa ideia também vem ao encontro das propostas de Nóvoa (2009) e Cerny, Almeida e Ramos (2014) que apregoam uma formação no coletivo da escola.

Outra ideia que merece destaque é a questão do compartilhamento das práticas pelos professores e alunos dentro de uma das ferramentas do AVA, a princípio chamada de "Blog". Durante as discussões sobre essa ferramenta uma professora diz: "Quero compartilhar no facebook". O fato de ter a iniciativa de compartilhar em redes sociais é muito positivo, pois traz a questão da comunicação. Apesar do AVA possuir essa possibilidade, a professora pensou em ir além, o que pode ser mais produtivo e alcançar uma comunidade mais específica.

Quando foi proposto que os professores elaborassem planos de aula que poderiam ser "postados" no AVA para que outros professores também pudessem acessá-lo e dele fazer o uso, alguns professores procuraram realizar tal tarefa com afinco. Surgiram ideias interessantes, mas ainda se percebeu a necessidade do resgate da autonomia e da autoestima do professor. Nóvoa, (2009) levanta essa questão em seus estudos. Todos são capazes e precisam ter ciência disso, reconhecendo-se como produtores de conhecimento e não apenas como receptores passivos de tudo aquilo que lhes é imposto.

\section{CONSIDERAÇÕES FINAIS}

No decorrer do encontro poucos professores opinaram e sugeriram mudanças para as ferramentas do AVA. Frequentemente alguns professores apenas descreviam as propostas já apresentadas por outros colegas nos cartões distribuídos. Entretanto, muitas das sugestões foram de grande valia para que se pudesse continuar no desenvolvimento do mesmo, agora atendendo às reais necessidades do grupo de professores.

O encontro com os professores revelou muitos obstáculos e o primeiro deles é o entendimento da proposta. Acredita-se que isso deva-se ao fato da finalidade com que se apresentou o encontro, pois, geralmente o que ocorre é os professores serem apresentados a ferramentas já prontas, em que são "treinados" para seu uso no decorrer do trabalho docente. O que se propôs foi uma inversão desse modelo, apresentando uma ferramenta em fase de construção, em que suas opiniões e anseios serão considerados. O intuito sempre foi o de ouvir os professores e de colocá-los como construtores da ferramenta.

O segundo obstáculo diz respeito à compreensão sobre a Estatística e Probabilidade. Muitos demonstraram certa dificuldade no decorrer do encontro, tornando-se mais reveladora na elaboração dos planos de aula. Uma discussão anterior sobre os conceitos referentes à temática poderia ter auxiliado na compreensão dos professores, entretanto, o tempo de que se dispunha não permitiu essa prática. Além disso, a proposta não previa esse tipo de ação. Isso demonstra a necessidade de formação que trate especificamente do conteúdo de Probabilidade e Estatística para os professores dos anos iniciais. 
Sem dúvida, a formação desse professor carece de atenção. Faz-se primordial que ao professor seja possibilitada a oportunidade desse conhecimento. Orientações e direcionamentos precisam ser dispostos para que esse docente consiga, em primeiro lugar, compreender a importância da Educação Estatística na vida cotidiana dos alunos e de si próprio, para que, ao longo de suas reflexões e de seu trabalho, possa mediar o conhecimento a respeito do tema.

Para essa formação é importante pensar em encontros em que haja a possibilidade do professor participar dentro de sua carga horária de trabalho: em seu expediente; do contrário, muitos resultados não serão conseguidos. Também é importante pensar em formações continuadas a distância. A EaD pode trazer contributos muito favoráveis para a formação em Educação Estatística para os professores. Há, ainda de se pensar em práticas que os coloquem cada vez mais como principais articuladores de propostas pedagógicas com o uso das TIC. 


\title{
Teaching of statistics and information and communication technology: between the teaching and technological resources development
}

\begin{abstract}
This article aims to present the analysis of a meeting with teachers in the early years of elementary school in which they were invited to participate in the process of developing a Virtual Learning Environment - VLE for teaching of statistics. The study of qualitative and interpretative, is part of a master's research in progress, and in this writing are pointed out some of the preliminary perceptions with this practice. In this way, the considerations of work with teachers were listed in categories that showing: i) teachers attitudes regarding ICT; ii) attitudes towards analysis and joint participation in the construction of VLE; iii) conceptions and attitudes towards Statistics and Probability; iv) perception of the VLE tools. This meeting with the teachers revealed many obstacles, both in understanding the proposal and in the understanding of probability and statistics, suggesting that continuing education processes that they pay attention more to aspects of teacher autonomy and basic knowledge of teaching today, are prioritized.
\end{abstract}

KEYWORDS: ICT. Teachers. VLE. Statistics. Probability. 


\section{REFERÊNCIAS}

ALMEIDA, Fernando José de. Educação e Informática: os computadores na escola. 5ed. São Paulo: Cortez, 2012.

BIANCHINI, Daiani Finatto. Perspectiva da estatística como elemento norteador do trabalho com conceitos matemáticos nos anos iniciais - questões epistemológicas e de formação. In: X ANPED SUL, 10, 2014, Florianópolis (SC). Anais... Florianópolis, 2014. p. 1-16. Disponível em: <http://xanpedsul.faed.udesc.br/arq_pdf/193-0.pdf>. Acesso em: 10 mar 2016.

BRASIL. Secretaria de Educação Básica. Diretoria de Apoio à Gestão Educacional. Pacto Nacional pela Alfabetização na Idade Certa: Educação Estatística. Ministério da Educação. Brasília: MEC, SEB, 2014.

CASTRO, Franciana Carneiro de; CAZORLA, Irene Mauricio. O papel da estatística na leitura do mundo: o letramento estatístico. Publicatio UEPG Ciências Humanas, Ciências Sociais Aplicadas, Linguística, Letras e Artes, Ponta Grossa, v. 16, n.1, p. 45-53, jun. 2008. Disponível em:

<http://www.revistas2.uepg.br/index.php/humanas/article/view/617/605>. Acesso em: 10 mai 2015.

CERNY, Rosely Zen; RAMOS, Edla; ALMEIDA, José Nilton de. Formação continuada de professores para a cultura digital. Revista Científica e-curriculum. ISSN 18093876, v. 12, n. 2, p. 1331-1347, 2014. Disponível em:

$<$ http://revistas.pucsp.br/index.php/curriculum/article/view/20425>. Acesso em: 9 maio 2015.

CIBOTTO, Rosefran Adriano Gonçales; OLIVEIRA, Rosa Maria Moraes Anunciato. O conhecimento tecnológico e pedagógico do conteúdo (TPACK) na formação inicial do professor de matemática. In: VIII Encontro de Produção Científica e Tecnológica, 8, 2013, Campo Mourão (PR). Anais... Campo Mourão: Fecilcam, 2013. p. 1-15. Disponível em:

$<$ http://www.fecilcam.br/nupem/anais viii epct/PDF/TRABALHOSCOMPLETO/Anais-CET/MATEMATICA/ragcibottotrabalhocompleto.pdf $>$. Acesso em: 09 mar 2016. educativo através de um projeto interdisciplinar. In: IV Congresso Brasileiro de Computação, 4, 2004, Itajaí (SC). Anais... Itajaí: UNIVALI, 2004. p. 223-228. 
Disponível em:

<http://www.niee.ufrgs.br/eventos/CBCOMP/2004/pdf/Informatica Educa\%E7\% E3o/t170100155 3.pdf>. Acesso em: 29 jun. 2015.

KENSKI, Vani Moreira. Educação e Tecnologias: o novo ritmo da informação. 8a ed. Campinas, SP: Papirus, 2012.

LANG, Affonso Manoel Righi; GONZÁLEZ, Fernando Jaime. A proposta teórica do conhecimento tecnológico pedagógico de conteúdo e a (sub)utilização das TIC na educação básica. In: Congreso Iberoamericano de Ciencia, Tecnología, Innovación y Educación, 2014, Buenos Aires. Anais... Buenos Aires, Argentina, 2014. p. 1-12. Disponível em: <http://www.oei.es/congreso2014/memoriactei/1283.pdf>. Acesso em: 10 mar 2016.

LOPES, Celi Espasandin. O ensino da estatística e da probabilidade na educação básica e a formação dos professores. Cadernos CEDES, v. 28, n. 74, p. 57-73, 2008. Disponível em:

<http://www.scielo.br/scielo.php?script=sci abstract\&pid=S01013262200800010 0005\&lng=en\&nrm=iso\&tlng=pt>. Acesso em: 4 jun. 2015.

MISHRA, Punya \& KOEHLER, M Matthew J. Technological Pedagogical Content Knowledge: A Framework for Teacher Knowledge. In: Teachers College Record, v. 108, n. 6, p. 1017-1054, 2006. Disponível em:

$<$ http://punya.educ.msu.edu/publications/journal articles/mishra-koehlertcr2006.pdf>. Acesso em 06 de mar. 2016.

MISHRA, Punya.; KOEHLER, M atthew. J. Introducing Technological Pedagogical Content Knowledge. In: Annual Meeting of the American Educational Research Association. New York City, March 24-28, 2008. Disponível em: $<$ http://punya.educ.msu.edu/presentations/AERA2008/MishraKoehler AERA200 8.pdf>. Acesso em 09 mar 2016.

NÓVOA, António. Professores: imagens do futuro presente. Educa: Lisboa, 2009.

PONTE, J. P. da. Tecnologias de informação e comunicação na formação de professores: que desafios? Revista Ibero Americana de Educação, n. 24, p. 63-90, 2000. Disponível em: <http://www.rieoei.org/rie24a03.htm>. Acesso em: 7 fev. 2016. Aparecida Gutiérrez de; ALTHAUS, Neiva. Formação continuada para professores dos anos iniciais do ensino fundamental: uso de tablets para ensinar matemática. In: Simpósio Internacional de Pesquisa em Educação Matemática, 4, 2015, Ilhéus (BA), Anais..., Ilhéus, 2015. p.2404-2415. 
<http://sipemat4.com.br/ocs/index.php/sipemat4/index/search/authors/view?fi rstName=Maria\&middleName=Madalena\&lastName=Dullius\&affiliation=Centro\% 20Universit\%C3\%A1rio\%20Univates\&country=BR>. Acesso em: 10 mar. 2016.

SANTOS, Raquel; PONTE, João Pedro. O desenvolvimento de investigações estatísticas: um estudo com futuros professores e educadores. In: J. M. Contreras, G. R. Cañadas, M. M. Gea y P. Arteaga (Eds.), Actas de las Jornadas Virtuales em Didáctica de la Estadística, Probabilidad y Combinatoria (pp. 455462). Granada, Departamento de Didáctica de la Matemática de la Universidad de Granada, 2013.

SHULMAN, Lee $S$. Those who understand: knowledge growth in teaching. Educational Researcher, Washington (EUA), v. 15, n. 2, p. 4-14, 1986.

VIEIRA, Márcia Lopes; JÚNIOR, Ailton Paulo de Oliveira; NETO, Julio Henrique da Cunha. Concepções de professores dos anos iniciais do ensino fundamental sobre o ensino de estatística. In: IV Seminário de Formação de Professores. 4, 2013 Uberaba (MG). Anais... Uberaba: UFTM, 2013. p. 1-4. Disponível em: <http://www.uftm.edu.br/seforprof/images/comunicacao/2.4 Concep\%C3\%A7\% C3\%B5es de Professores dos anos iniciais do Ensino Fundamental sobre 0 ensino de Estat\%C3\%ADstica.pdf> . Acesso em 7 fev. 2016.

Recebido: 06 de abr. de 2016.

Aprovado: 20 de abr. de 2016

DOI: $10.3895 /$ rbect.v9n1.3875

Como citar:

DIAS, C. F. B.; JUNIOR, G. S. Ensino de estatística e tecnologias da informação e comunicação: entre a docência e o desenvolvimento de recursos tecnológicos. Revista Brasileira de Ensino de Ciência e

Tecnologia, v. 9, n. 1, p. 228-246, jan./abr. 2016. Disponível em:

<https://periodicos.utfpr.edu.br/rbect/article/view/3875>. Acesso em: xxx. Correspondência:

Cristiane de Fatima Budek Dias

Rua Dr. Chafic Cury, 310, 84015-700, Ponta Grossa, Paraná

Guataçara dos Santos Junior

Av Monteiro Lobato, s/n, Km 04 CEP 84016-210, Ponta Grossa, Paraná

Direito autoral: Este artigo está licenciado sob os termos da Licença Creative Commons-Atribuição 4.0 Internacional. 